\title{
Spectrophotometric determination and spectroscopic studies on Schiff base and charge transfer complex of ketorolac tromethamine
}

\author{
Nasrin Banu Shaikh Ismail and Badiadka Narayana*
}

\begin{abstract}
Background: Ketorolac tromethamine is a versatile analgesic drug used extensively for the treatment of fever and moderate to severe pain. It is a potent non-steroidal anti-inflammatory drug that extends opioid-level analgesia to patients. Two new selective methods are proposed for spectrophotometric determination of ketorolac tromethamine (KT) in pure and pharmaceutical formulation.

Methods: The determination procedures are based on the condensation reaction of $K T$ with 2,4-dinitrophenylhydrazine $(\mathrm{DNPH})$ in strongly alkaline medium resulting in the formation of red-colored hydrazones which is quantitated at $424 \mathrm{~nm}$ for method $\mathrm{A}$ and method $\mathrm{B}$ involves the charge transfer reaction between $\mathrm{KT}$ as electron donor and $7,7^{\prime}, 8,8^{\prime}$-tetracyanoquinodimethane (TCNQ) as $\pi$-acceptor to form dark green-colored complex which is measured at $842 \mathrm{~nm}$.

Results: Linear correlation is obtained in the range $0.50-18.50 \mu \mathrm{g} \mathrm{mL}^{-1}$ and $2.00-50.00 \mu \mathrm{g} \mathrm{mL}^{-1}$ with detection limits of 0.1579 and $0.3721 \mathrm{mg} \mathrm{mL}^{-1}$ for method $A$ and method B, respectively. The optimum analytical conditions are analyzed, and the proposed assay is validated as per the ICH guidelines.

Conclusions: The developed methods are effectively applied to the determination of KT in tablets, injections, and ophthalmic formulations with good percentage recoveries. The final reaction products are characterized by spectral analysis (FT-IR and ${ }^{1} \mathrm{H}$ NMR). In addition, the surface morphology of the reaction products are also studied using scanning electron microscopy.
\end{abstract}

Keywords: Schiff base, 2,4-Dinitrophenylhydrazine, Charge transfer, TCNQ, Spectral characterization

\section{Background}

Ketorolac tromethamine (KT) is a non-steroidal antiinflammatory drug (NSAID) which is widely used as nonnarcotic substitute to opioid analgesics. It belongs to a class of heterocyclic acid derivatives with chemical name, $( \pm)-5$ benzoyl-2,3-dihydro- $1 H$-pyrrolizine-1-carboxylic acid and 2-amino-2-(hydroxymethyl)-1,3-propanediol (Fig. 1). KT is a prostaglandin synthetase-inhibiting analgesic with rapid onset of action and prolonged efficacy in the short-term management of acute pain (Resman-Targoff 1990; Stanski et al. 1990). It has also been indicated in ameliorating

\footnotetext{
* Correspondence: nbadiadka@yahoo.co.uk

Department of Post Graduate Studies and Research in Chemistry, Mangalore University, Mangalagangothri 574199, Karnataka, India
}

severe postoperative pain related with abdominal, gynecologic, oral, and orthopedic surgery (Litvak and McEvoy 1990). Unlike opiate analgesics, KT is well tolerated with diminished rates of opioid-induced adverse events making it an effective alternative for reducing ocular inflammation and for the symptomatic relief of acute renal colic, pain associated with trauma, and visceral pain associated with cancer (Litvak and McEvoy 1990; Brown et al. 1990). The desired anti-inflammatory effect is due to the reduction in formation of precursors of prostaglandin which is believed to be caused by the inhibition of both cyclooxygenase- 1 (COX-1) and cyclooxygenase-2 (COX-2) enzymes. The resultant decrease in prostaglandin activity effectively 


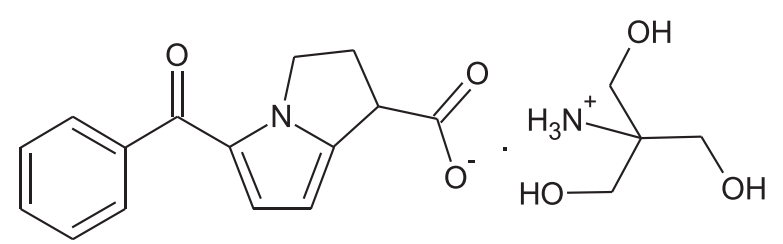

Fig. 1 Chemical structure of ketorolac tromethamine

blocks the generation of pain impulse, thereby contributing to the analgesic effect of this medication (Blais et al. 2002).

KT is an off-white crystalline powder freely soluble in methanol, and it exists in the anionic form, in particular, at physiological $\mathrm{pH}$. It is a racemate of $[-] \mathrm{S}-$ and $[+] \mathrm{R}-$ enantiomeric forms, with the $\mathrm{S}$-form exhibiting the therapeutic activity. To enhance the water solubility and render the drug fairly appropriate for parenteral administration (Buckley and Brogden 1990), it is formulated as tromethamine salt and administered intramuscularly, intravenously, as a topical ophthalmic solution and also orally as a continuation therapy to injection (Sinha et al. 2009). The analgesic efficacy of KT appears to be superior to morphine or meperidine because it lacks the depressant effects of opioids. Because of its enhanced importance over morphine, it is widely preferred as an analgesic drug over opiate comparators in controlling postsurgical pain [DeAndrade et al. 1994].

The great clinical significance of KT in medicinal field has led to an extensive literature on its determination in pharmaceutical formulation. A survey of literature revealed that the KT has been analyzed in pharmaceutical preparations either alone or in combination with other drugs by HPLC (Kumaraswamy et al. 2012; Razzaq et al. 2012; Tsvetkova et al. 2012; Dave et al. 2013; Dubey et al. 2012), HPTLC (Devarajan et al. 2000; Vandana et al. 2013), voltammetry (Squella et al. 1997), and micellar electrokinetic chromatography (Orlandini et al. 2004). Though these analytical procedures are sensitive, it entails a disadvantage of not being simple and requiring sophisticated experimental setup, increased cost of analysis and high consumption of solvents by the mobile phase for the chromatographic techniques. Therefore, it is essential to develop simple, rapid, and reproducible methods that can be adapted for routine analysis of KT in quality control laboratories. In recent times, spectrophotometry has been successfully employed as a quantitative technique for the determination of drugs in bulk and formulations.

Derivative spectrophotometric methods (Jitendra et al. 2009; Yatri et al. 2013; Ramzia et al. 2013) and quite a few visible spectrophotometric methods (Rajasekaran 1995; Pratapareddy and Chakravarthi 2012; Kamath et al. 1994; Arshiya et al. 2012; Dattaray and Uday 1997;
Sawsan et al. 2013) are reported in literature for quantitative determination of $\mathrm{KT}$ in bulk and dosage forms. The purpose of this study is to develop simple, accurate, and economical methods for the determination of KT using 2,4-dinitrophenylhydrazine (DNPH) and $7,7^{\prime}, 8,8^{\prime}$-tetracyanoquinodimethane (TCNQ) as reagents. Optimization of various experimental conditions, stoichiometry, and mechanism of the proposed reactions are studied. The suggested methods have high sensitivity and are validated as per ICH guidelines and rely on the use of non-expensive technique and affordable easily available chemicals. The application of the proposed methods is explored by employing these methods for the microdetermination of $\mathrm{KT}$ in its pharmaceutical dosage forms. Attempts have also been made to synthesize and characterize the reaction products using spectroscopic techniques.

\section{Methods}

\section{Instrumentation and physical measurements}

Spectrophotometric measurements were performed on SHIMADZU UV-2550 double beam spectrophotometer equipped with $1-\mathrm{cm}$ matched quartz cells. The infrared spectra within the range of $4000-400 \mathrm{~cm}^{-1}$ for the free reactants and the reaction products were recorded using $\mathrm{KBr}$ disc on SHIMADZU FT-IR-Prestige-21 spectrometer. ${ }^{1} \mathrm{H}$ NMR spectra $(400 \mathrm{MHz})$ were recorded on AV400 spectrometer using DMSO- $\mathrm{d}_{6}$ as a solvent and TMS as the internal reference standard. Scanning electron microscopy (SEM) images were taken in Zeiss Sigma instrument equipped with GEMINI column, with an accelerating voltage of $2.00 \mathrm{kV}$.

\section{Materials and reagents}

Pure sample of ketorolac tromethamine (KT) was provided by CAD Pharma Inc., Bangalore, India. The following pharmaceutical formulations were procured from commercial source: Ketorol ${ }^{\text {mm }}$ tablets (Dr. Reddy's Laboratories Ltd., India) labeled to contain $10 \mathrm{mg}$ of ketorolac tromethamine per tablet, Ketorol ${ }^{\text {m" }}$ vials (Dr. Reddy's Laboratories Ltd., India) labeled to contain $30 \mathrm{mg}$ of ketorolac tromethamine in $1 \mathrm{~mL}$ of sterile solution, and Ketlur sterile ophthalmic solution (Sun Pharmaceutical Industries Ltd., India) labeled to contain $5 \mathrm{mg}$ of ketorolac tromethamine per milliliter of aqueous solution.

Analytical reagent grade 2,4-dinitrophenylhydrazine and potassium hydroxide were purchased from $\mathrm{BDH}$ chemicals. The reagent $7,7^{\prime}, 8,8^{\prime}$-tetracyanoquinodimethane was obtained from Sigma-Aldrich. Spectroscopic grade methanol and acetonitrile solvents were supplied by Spectrochem. 
Preparation of standard stock and reagent solutions

The stock standard solutions of KT $\left(100 \mu \mathrm{g} \mathrm{mL}{ }^{-1}\right)$ were prepared by dissolving precisely weighed $10 \mathrm{mg}$ of pure drug in $100 \mathrm{~mL}$ of methanol and acetonitrile for method A and method B, respectively. The working concentrations were prepared by approximate dilution of standard drug solution.

The reagent solution of DNPH was prepared at a concentration of $5 \times 10^{-3} \mathrm{M}$ in methanol, and TCNQ was prepared at a concentration of $5 \times 10^{-4} \mathrm{M}$ in acetonitrile solvent. The stock solutions were freshly prepared and protected from light.

\section{General analytical procedures}

Determination of KT based on the measurement of Schiff base (method A)

Aliquots containing $0.50-18.50 \mu \mathrm{g} \mathrm{mL}^{-1}$ of standard KT $\left(100 \mu \mathrm{g} \mathrm{mL}^{-1}\right)$ were transferred quantitatively to $10 \mathrm{~mL}$ calibrated standard flasks. To that, $1 \mathrm{~mL}$ of DNPH solution was added followed by addition of $1 \mathrm{~mL}$ of $2 \mathrm{~N}$ methanolic potassium hydroxide and the volume was brought to $5 \mathrm{~mL}$ with methanol. The solutions were incubated in water bath at $60{ }^{\circ} \mathrm{C}$ for $15 \mathrm{~min}$. The solutions were cooled to room temperature and diluted up to the mark using methanol, and absorbances were measured at $424 \mathrm{~nm}$ against the reagent blank.

\section{Determination of KT based on the measurement of charge transfer (method B)}

Aliquots containing $2.00-50.00 \mu \mathrm{g} \mathrm{mL}^{-1}$ of standard $\mathrm{KT}$ $\left(100 \mu \mathrm{g} \mathrm{mL}^{-1}\right)$ were transferred quantitatively to $10 \mathrm{~mL}$ calibrated standard flasks. To each flask, $2 \mathrm{~mL}$ of TCNQ was added and the reaction mixture was heated at $50{ }^{\circ} \mathrm{C}$ for $10 \mathrm{~min}$. The solutions were then cooled and completed to the volume with acetonitrile solvent, and absorbances were measured at $842 \mathrm{~nm}$ against the reagent blank.

\section{Analysis of pharmaceutical formulation Tablets}

The contents of 20 tablets were pulverized to fine powder, and an amount equivalent to $10 \mathrm{mg}$ was accurately weighed and dissolved in $50 \mathrm{~mL}$ methanol and acetonitrile for method $\mathrm{A}$ and $\mathrm{B}$, respectively. The solutions were swirled for $10 \mathrm{~min}$ and filtered through Whatmann No. 40 filter paper into two separate 100-mL standard flasks which was then diluted to the mark with respective solvents. A convenient aliquot from the resulting solutions was then subjected to analysis.

\section{Injection vials}

The contents of two injection vials, each having an amount equivalent to $30 \mathrm{mg}$ of active ingredient was filtered through Whatmann No. 40 filter paper and transferred into two separate $100-\mathrm{mL}$ calibrated flask. It was then dissolved with methanol and acetonitrile for method A and B, respectively. The solutions were mixed well and completed to the volume with respective solvents. A convenient aliquot from resulting solutions was then subjected to analysis.

\section{Ophthalmic solutions}

An accurately measured volume equivalent to $5 \mathrm{mg}$ was dissolved in $25 \mathrm{~mL}$ methanol and acetonitrile for method $A$ and $B$, respectively. The solutions were then mixed well and filtered through Whatmann No. 40 filter paper. The filtrates were collected in two separate $50-\mathrm{mL}$ calibrated flasks and diluted to the mark with respective solvents. A convenient aliquot from resulting solutions was then subjected to analysis.

\section{Synthesis of solid reaction products}

The synthesis of KT-DNPH product was done by refluxing a mixture of $\mathrm{KT}(1 \mathrm{mmol}, 0.3764 \mathrm{~g})$ and $\mathrm{DNPH}$ (1 mmol, $0.1981 \mathrm{~g}$ ) in $50 \mathrm{~mL}$ of methanol in basic medium for $4 \mathrm{~h}$. The reaction mixture was allowed to cool and filtered to obtain red-colored solid precipitate, which was then washed with cold water and recrystallized from acetonitrile solvent. The solid charge transfer complex KT-TCNQ was synthesized by mixing an equimolar concentration of KT $(0.50 \mathrm{mmol}, 0.1882 \mathrm{~g})$ and TCNQ $(0.50 \mathrm{mmol}, 0.1020 \mathrm{~g})$ in $40 \mathrm{~mL}$ of acetonitrile, and the mixture was stirred well at room temperature for half an hour. The product was then filtered, washed with acetonitrile, and dried.

\section{Results and discussion}

The reaction of carbonyl functionality with DNPH is the most popular and widely studied for the quantitative measurement of trace quantities of carbonyl content in variety of organic mixtures (Dasgupta et al. 1994). The keto group of the drug KT is condensed with DNPH to form 2,4-dinitrophenylhydrazone, and in strongly alkaline conditions, the hydrazones form wine red-colored product of quinonoid structure (Dasgupta et al. 1994) showing maximum absorption at $424 \mathrm{~nm}$. This forms the basis of measurement principle for the determination of KT by method A. The second method B involves exploring the charge transfer reaction of $\mathrm{KT}$ with TCNQ. The tertiary nitrogen atom present in the pyrrolizine moiety acts as the electron donor, donating electrons to $\pi$-acceptors like TCNQ to form deep green-colored complex which absorbs maximally at $842 \mathrm{~nm}$. The electronic absorption spectra of $\mathrm{KT}$ and its reaction products are shown in Fig. 2, and the probable reaction mechanism is depicted in Fig. 3. 


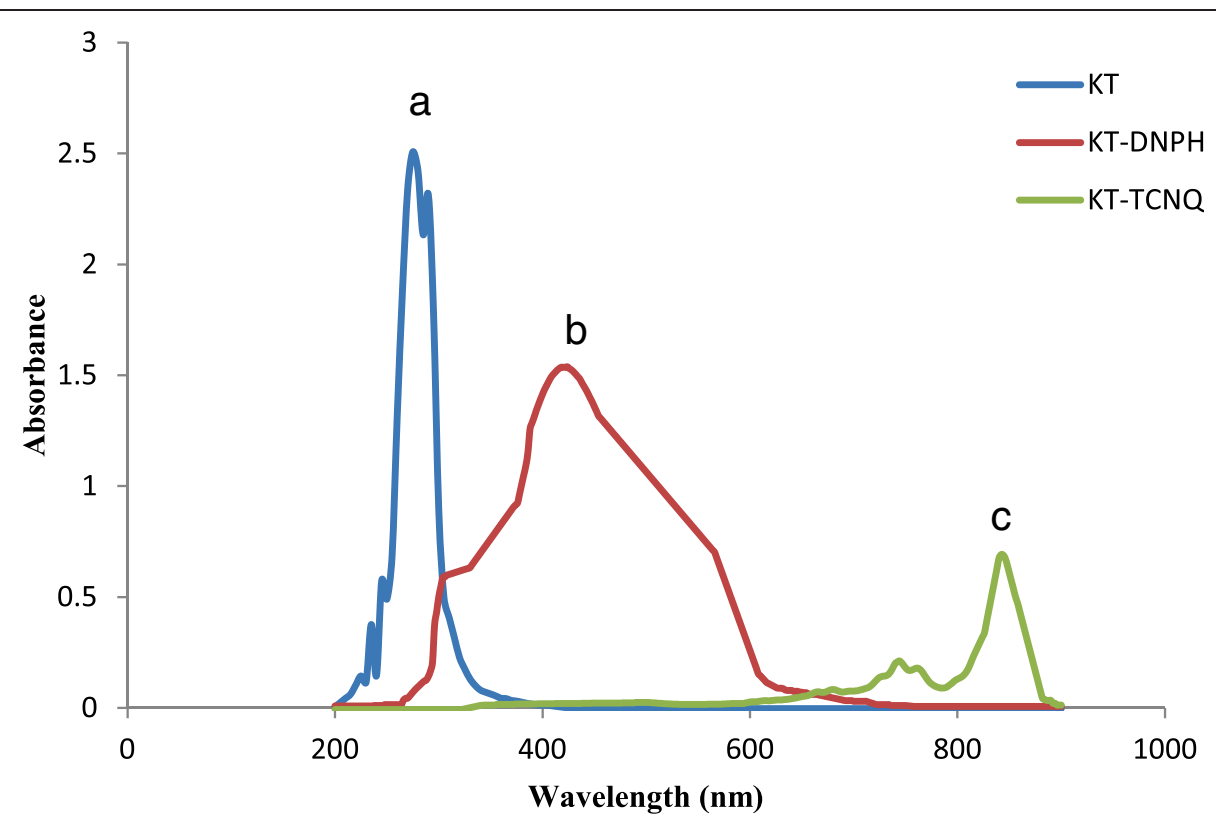

Fig. 2 Electronic absorption spectra of a pure KT, b KT-DNPH, and c KT-TCNQ

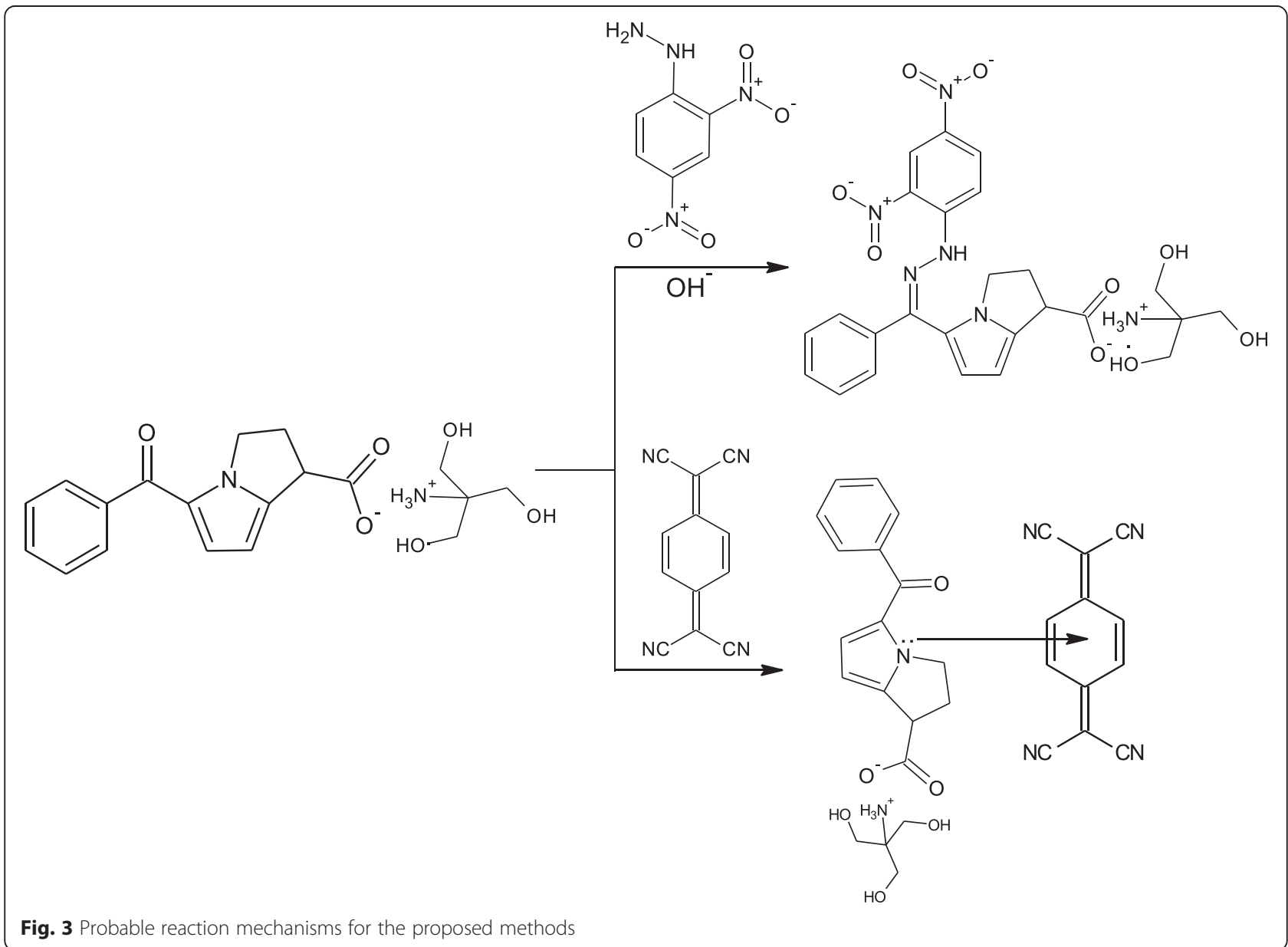




\section{Optimization of reaction parameters}

In order to achieve maximum sensitivity and selectivity, the proposed spectrophotometric methods are optimized by carefully studying the different reaction variables affecting the reaction. The optimum experimental conditions are established by studying the influence of one parameter on the absorbance values of colored species and in turn keeping the other parameter constant.

\section{Effect of solvent}

The effect of different solvents like methanol, ethanol, acetone, acetonitrile, water, and 1,4-dioxane has been studied for the proposed methods (Fig. 4). For method A, diluting with methanol gave the highest color intensity of Schiff base product and thus it is chosen as the ideal solvent. For method B, acetonitrile is observed to be the best solvent owing to its high dielectric constant and good solvating capacity for $\pi$-acceptors. However, water is not suitable for both the methods due to limited solubility of reagents.

\section{Effect of heating time and temperature}

The effect of time is studied by following the complete color development at different time intervals. The results obtained (Fig. 5) indicated that maximum absorbance is attained at $15 \mathrm{~min}$ for method $\mathrm{A}$ and $10 \mathrm{~min}$ for method $\mathrm{B}$. The optimum temperature to carry out the reaction is determined by following the absorption intensity at different temperatures ranging from $30-80{ }^{\circ} \mathrm{C}$. Maximum absorbance values are obtained at $60{ }^{\circ} \mathrm{C}$, and the reaction product remained stable for $3 \mathrm{~h}$ in method $\mathrm{A}$. In method $\mathrm{B}$, heating at $50{ }^{\circ} \mathrm{C}$ is sufficient and the product remained stable for $24 \mathrm{~h}$.

\section{Effect of reagent volume}

For method A, the effect of different volumes of particular concentrations of DNPH and potassium hydroxide on fixed concentration of $\mathrm{KT}$ is investigated. It is found that reproducible absorbance value is obtained with $1 \mathrm{~mL}$ of $0.005 \mathrm{M} \mathrm{DNPH}$ and $1 \mathrm{~mL}$ of $2 \mathrm{~N}$ potassium hydroxide. Excess addition of base is avoided because stable results are not obtained and also the color of blank solution remains dark for long time. For method $B$, various volumes of TCNQ solutions are added to fixed drug concentration and the results show that $2 \mathrm{~mL}$ of $0.0005 \mathrm{M}$ is adequate for reproducible and maximum color absorbance.

\section{Stoichiometry of reaction}

The molar ratio of drug to reagent is analyzed by employing Job's method of continuous variation (House 2013). At the optimum wavelength, the composition of KT-TCNQ reaction product is found to be $1: 1$. The stoichiometric relationship is illustrated in Fig. 6.

\section{Validation of methods}

The developed methods are validated with respect to linearity, accuracy and precision, specificity, limit of detection, and quantification according to the guidelines set by International Conference on Harmonization ( $\mathrm{ICH}$ Q2 R1 2005).

\section{Linearity and sensitivity}

The proposed methods conform to Beer's Law, and linear relationship (Fig. 7) in the absorbanceconcentration plot is obtained in the concentration range of $0.50-18.50 \mu \mathrm{g} \mathrm{mL} \mathrm{m}^{-1}$ for method A and 2.00-

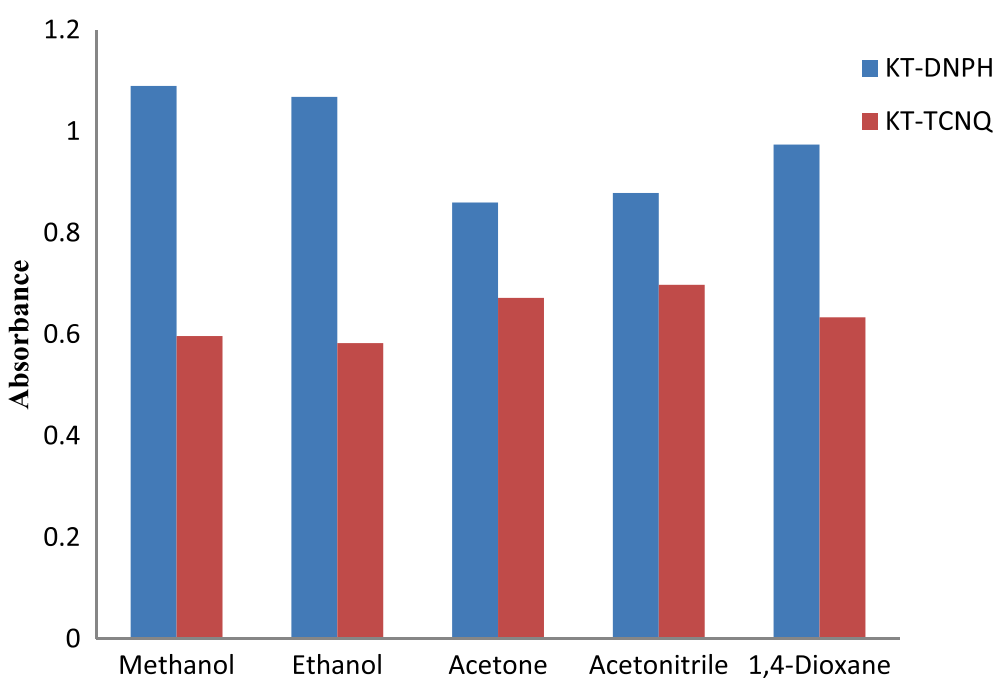

Fig. 4 Effect of solvent on the reaction of KT with DNPH and TCNQ 


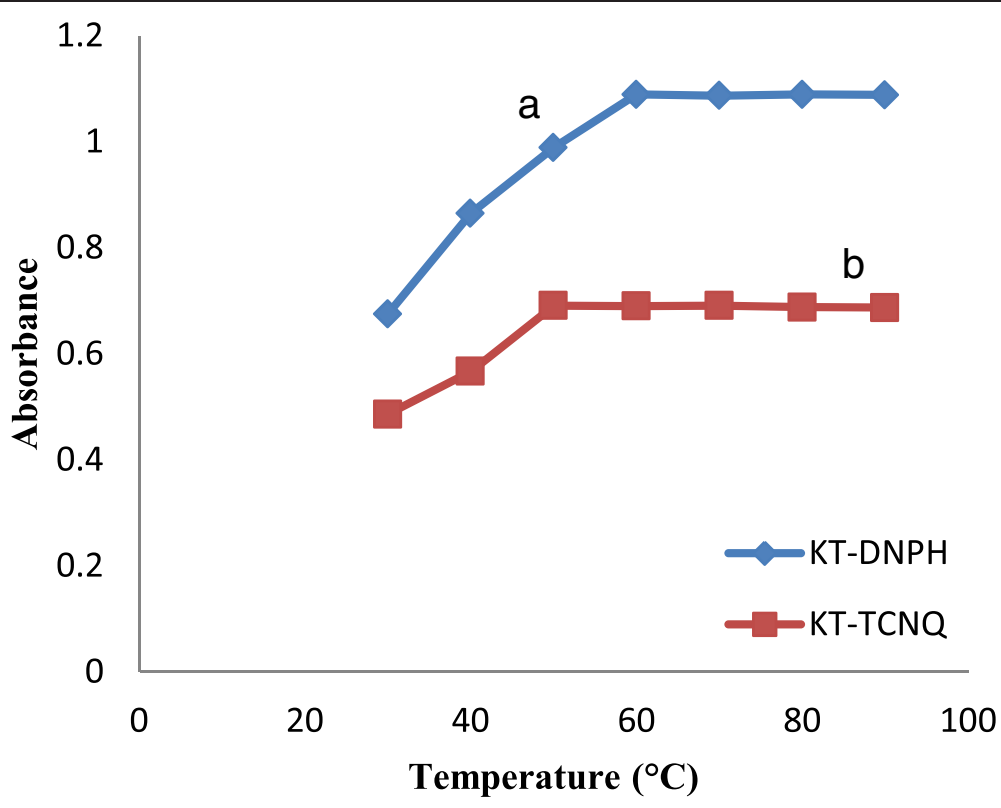

Fig. 5 Effect of temperature on the reaction of $K T$ with $\mathbf{a} D N P H$ and $\mathbf{b}$ TCNQ

$50.00 \mu \mathrm{g} \mathrm{mL} \mathrm{m}^{-1}$ for method B. The following equations have been obtained by the regression analysis of the linear plot. For method A, $Y=0.0531+0.0564 X, r=0.9985$ and for method B, $Y=0.0112+0.0133 X, r=0.9992$, where $Y$ is the absorbance and $X$ is the concentration of drug in $\mu \mathrm{g}$ $\mathrm{mL}^{-1}$ and $r$ is the correlation coefficient. Various optical and sensitivity parameters like molar absorptivity and Sandell's sensitivity are also computed and compiled in Table 1 . The results indicate good sensitivity of the proposed methods.

\section{Limit of detection and quantification}

The detection limit (LOD) and quantification limit (LOQ) is determined by evaluating the minimum level at which the active ingredient can be detected and quantified, respectively, with reliable accuracy and precision. The following expression was used: $\mathrm{LOD}=3.3 \mathrm{\sigma} / \mathrm{s}$ and $\mathrm{LOQ}=10 \mathrm{\sigma} / \mathrm{s}$ where $\sigma$ is the standard deviation of the values obtained by replicate determination of blank and $s$ is the slope of the calibration curve. The calculated values of LOD and LOQ are summarized in Table 1.

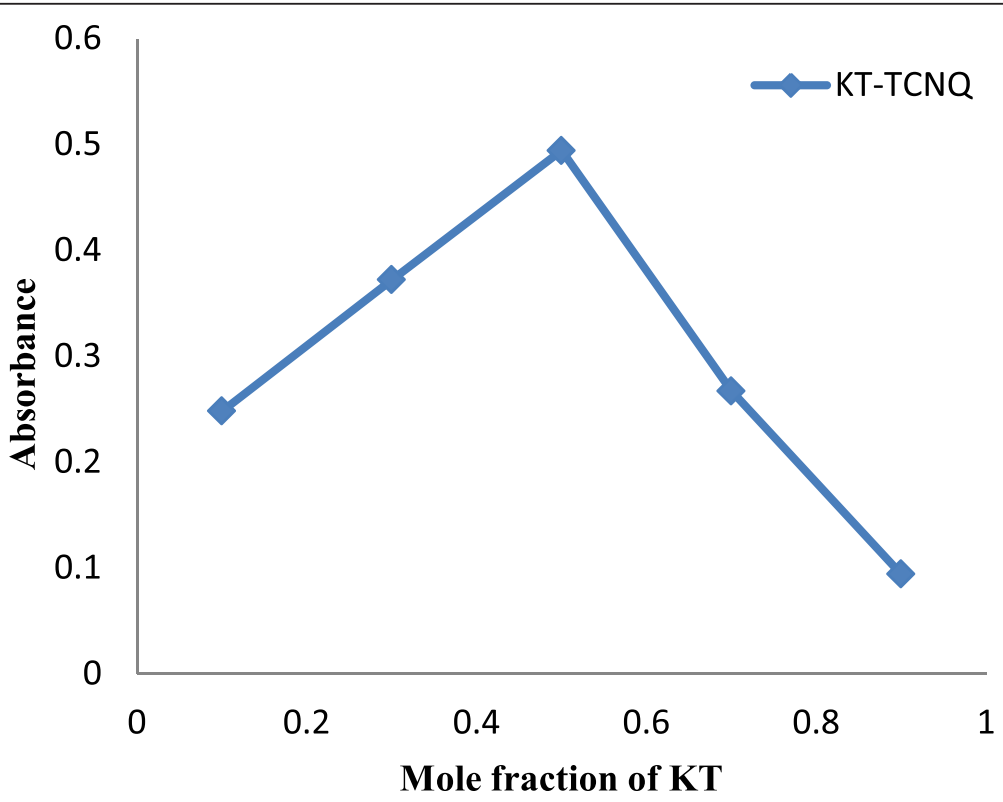

Fig. 6 Job's continuous variation plot of KT-TCNQ at detectable peak $842 \mathrm{~nm}$ 


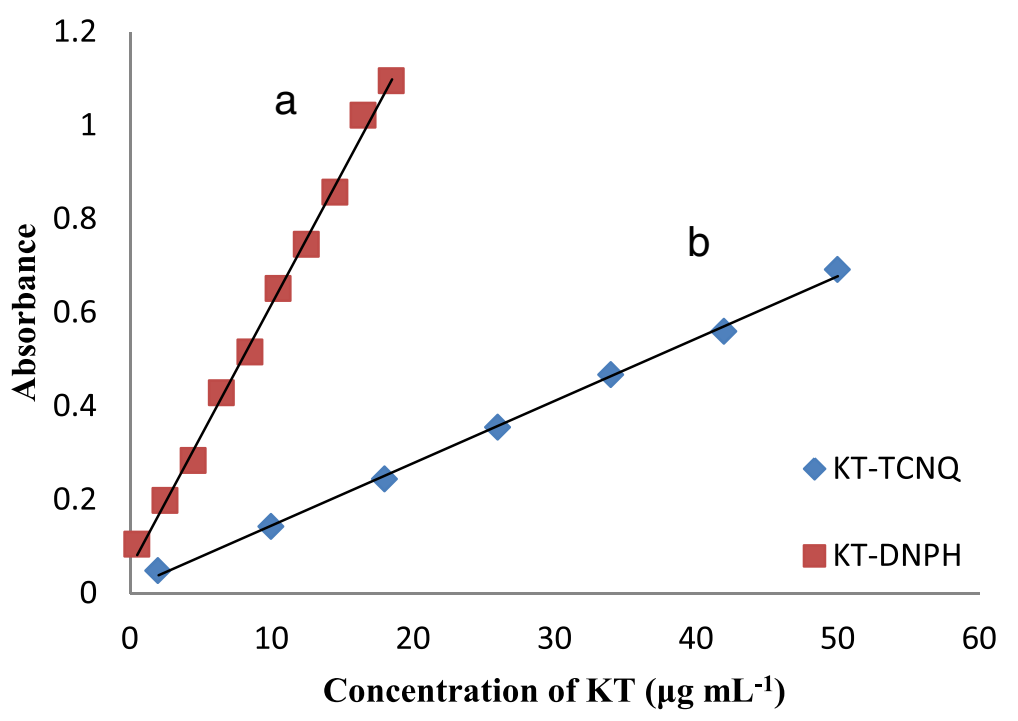

Fig. 7 Calibration graphs of proposed methods a KT-DNPH and b KT-TCNQ

\section{Accuracy and precision}

The accuracy and precision of proposed methods are determined by intraday and interday analysis of $\mathrm{KT}$ at three different concentration levels within optimized linearity range, and each concentration was replicated five times and presented in Table 2. The results are reported as percentage relative error (RE \%) and percentage relative standard deviation (RSD \%) which indicates the accuracy and precision of methods, respectively. The RE \% and RSD \% values thus obtained is less than $2 \%$ which demonstrates good accuracy and precision of the methods.

\section{Specificity}

The specificity or the selectivity of the proposed methods is studied by specifically analyzing the drug in the presence of other non-medicinal ingredients that

Table 1 Spectral parameters and statistical data of the regression equation

\begin{tabular}{lll}
\hline Parameters & Method A & Method B \\
\hline$\lambda$ max $(\mathrm{nm})$ & 424 & 842 \\
Beer's law limits $\left(\mu \mathrm{g} \mathrm{mL}^{-1}\right)$ & $0.50-18.50$ & $2.00-50.00$ \\
Molar absorptivity $\left(\mathrm{L} \mathrm{mol}^{-1} \mathrm{~cm}^{-1}\right)$ & $0.7829 \times 10^{5}$ & $0.9033 \times 10^{4}$ \\
Sandell sensitivity $\left(\mu \mathrm{g} \mathrm{cm}^{-2}\right)$ & $0.4807 \times 10^{-2}$ & $4.1666 \times 10^{-2}$ \\
Limit of detection $\left(\mu \mathrm{g} \mathrm{mL}^{-1}\right)^{\mathrm{a}}$ & 0.1579 & 0.3721 \\
Limit of quantification $\left(\mu \mathrm{g} \mathrm{mL}^{-1}\right)^{\mathrm{a}}$ & 0.4787 & 1.1278 \\
Regression equation & $Y=a+b X$ & $Y=a+b X$ \\
Intercept $(a)$ & 0.0531 & 0.0112 \\
Slope $(b)$ & 0.0564 & 0.0133 \\
Correlation coefficient $(r)$ & 0.9985 & 0.9992 \\
\hline
\end{tabular}

aimit of quantification and detection is calculated according to the $\mathrm{ICH}$ guidelines

${ }^{\mathrm{b}} Y$ is the absorbance and $X$ is the concentration in $\mu \mathrm{g} \mathrm{mL}^{-1}$ forms the matrix in formulation. The standard addition method was employed to study the influence of common excipients found in the selected pharmaceutical formulation such as microcrystalline cellulose, lactose, polyethylene glycol, sodium chloride, and magnesium stearate. Satisfactory percentage recovery values tabulated in Table 3 indicates that the excipients did not interfere with the determination of drug by the proposed spectrophotometric methods.

\section{Application to the analysis of formulation}

The developed methodology is applied to the determination of KT in three different pharmaceutical formulations. As can be seen from Table 3, the results of the assay are in good accordance with the label claim. The accuracy and reliability of the proposed assay are confirmed by applying the statistical tests such as Student's $t$ test. It is found that experimental $t$-value is smaller than the theoretical tabulated value at $95 \%$ confidence interval and five degrees of freedom. Appreciable percentage recovery values in the range of $100.03-100.40 \%$ and $99.90-100.03 \%$ are obtained for method A and method B, respectively, which strongly suggests non-interference of pharmaceutical adjuvant in the proposed assay.

\section{Characterization of reaction products FTIR spectra}

The infrared spectra of the synthesized reaction products KT-DNPH and KT-TCNQ are depicted in Fig. 8. The analysis of main infrared peaks of KT-DNPH and KT-TCNQ suggests the formation of Schiff base and charge transfer complexation, respectively. In the infrared (IR) spectra of KT-DNPH product, the appearance 
Table 2 Accuracy and precision data for the determination of $K T$ by the proposed methods

\begin{tabular}{|c|c|c|c|c|c|c|c|}
\hline \multirow[t]{2}{*}{ Methods } & \multirow[t]{2}{*}{ KETO taken $\left(\mu \mathrm{g} \mathrm{mL^{-1 } )}\right.$} & \multicolumn{3}{|l|}{ Intraday $(n=5)$} & \multicolumn{3}{|l|}{ Interday $(n=5)$} \\
\hline & & KETO found ${ }^{a} \pm S D\left(\mu \mathrm{gl}^{-1}\right)$ & RE (\%) & RSD (\%) & KETO found ${ }^{\mathrm{a}} \pm \mathrm{SD}\left(\mu \mathrm{g} \mathrm{mL^{-1 } )}\right.$ & RE (\%) & RSD (\%) \\
\hline \multirow[t]{3}{*}{ Method A } & 2.5 & $2.47 \pm 0.02$ & 1.20 & 0.81 & $2.51 \pm 0.03$ & 0.40 & 1.52 \\
\hline & 6.5 & $6.46 \pm 0.02$ & 0.61 & 0.30 & $6.51 \pm 0.06$ & 0.27 & 1.04 \\
\hline & 10.5 & $10.51 \pm 0.05$ & 0.09 & 0.48 & $10.47 \pm 0.06$ & 0.21 & 0.61 \\
\hline \multirow[t]{3}{*}{ Method B } & 10 & $10.04 \pm 0.08$ & 0.40 & 0.79 & $10.01 \pm 0.13$ & 0.10 & 1.29 \\
\hline & 26 & $26.02 \pm 0.12$ & 0.07 & 0.46 & $25.88 \pm 0.11$ & 0.46 & 0.42 \\
\hline & 34 & $34.02 \pm 0.12$ & 0.05 & 0.35 & $33.82 \pm 0.08$ & 0.52 & 0.23 \\
\hline
\end{tabular}

$S D$ standard deviation, $R S D$ relative standard deviation, $R E$ relative error

${ }^{a}$ Mean value of five determinations

of strong absorption band at 1622 and $3277 \mathrm{~cm}^{-1}$ is assigned to the stretching vibration of $\mathrm{C}=\mathrm{N}$ and $-\mathrm{NH}$ group, respectively, which confirms the formation of azomethine functional group. The intense band at 1737 and $1587 \mathrm{~cm}^{-1}$ is assigned to the carboxylate ester group and bending vibrations for $\mathrm{N}-\mathrm{H}$ group in pure drug $\mathrm{KT}$. The infrared spectra of charge transfer complex KTTCNQ are characterized by the appearance of main bands of both donors and acceptors but show small shifts in both wave number values and band intensities compared to those of reactants which give conclusive evidence of charge transfer complexation. These shifts could be concerned with changes in molecular symmetry and electronic structure upon complex formation (Abeer et al. 2013). In the IR spectrum of pure KT, the stretching $\mathrm{C}-\mathrm{N}$ frequency is shifted from 1309 to $1400 \mathrm{~cm}^{-1}$ in the CT complex, suggesting that electron transition of $n$ to $\pi^{*}$ occurs from $\mathrm{C}-\mathrm{N}$ site of pyrrolizine moiety of $\mathrm{KT}$. The frequency of $\mathrm{C} \equiv \mathrm{N}$ and $\mathrm{C}=\mathrm{C}$ is observed at 2222 and $1543 \mathrm{~cm}^{-1}$ in free TCNQ molecule which is shifted to 2129 and $1597 \mathrm{~cm}^{-1}$ in IR graph of KT-TCNQ,

Table 3 Determination of KT in dosage forms by the proposed methods

\begin{tabular}{|c|c|c|c|}
\hline \multirow[t]{2}{*}{ Brand name } & \multirow{2}{*}{$\begin{array}{l}\text { Labeled } \\
\text { amount (mg) }\end{array}$} & \multicolumn{2}{|c|}{ Amount found $^{a} \pm S D$} \\
\hline & & Method A & Method B \\
\hline \multirow[t]{3}{*}{ Ketorol } & 10 & $10.04 \pm 0.09$ & $9.99 \pm 0.08$ \\
\hline & & $t$ test $^{\mathrm{b}}=0.95$ & $t$ test $^{\mathrm{b}}=0.50$ \\
\hline & & $\% \operatorname{Rec}^{c}=100.40$ & $\% \operatorname{Rec}^{c}=99.90$ \\
\hline \multirow[t]{3}{*}{ Ketorol (IM/IV) } & 30 & $30.01 \pm 0.01$ & $30.01 \pm 0.03$ \\
\hline & & $t$ test $^{\mathrm{b}}=0.78$ & $t$ test $^{\mathrm{b}}=0.99$ \\
\hline & & $\% \operatorname{Rec}^{c}=100.03$ & $\% \operatorname{Rec}^{c}=100.03$ \\
\hline \multirow{3}{*}{$\begin{array}{l}\text { Ketlur sterile } \\
\text { eye drops }\end{array}$} & 5 & $5.01 \pm 0.05$ & $5.00 \pm 0.06$ \\
\hline & & $t$ test $^{\mathrm{b}}=1.74$ & $t$ test $^{\mathrm{b}}=0.17$ \\
\hline & & $\% \operatorname{Rec}^{c}=100.20$ & $\% \operatorname{Rec}^{c}=100.00$ \\
\hline
\end{tabular}

${ }^{a}$ Mean value of five determinations

${ }^{\mathrm{b}}$ Theoretical $t$-value at $95 \%$ confidence level is 2.78

${ }^{\mathrm{c}}$ Recovery respectively. The aromatic ring of TCNQ is electron deficient in nature due to the presence of four electron withdrawing cyano groups attached to it. The electron donation process from HUMO of the donor to LUMO of acceptor increases the charge density on $\mathrm{CN}$ group of TCNQ thus decreases the CN bond order, and hence, lower vibrational wave number is observed after complexation (Adam 2012; Adam and Refat 2014; Refat et al. 2014; Refat et al. 2015).

\section{${ }^{1} H$ NMR spectra}

The ${ }^{1} \mathrm{H}$ NMR spectra of reaction products KT-DNPH and KT-TCNQ are given in Fig. 9. In the spectra of KT$\mathrm{DNPH}$, the appearance of singlet peak integrating for one proton at $\delta 11.01 \mathrm{ppm}$ confirms formation of azomethine group. Furthermore, multiplets are observed for Schiff base product in the range $\delta 5.96-8.79 \mathrm{ppm}$ which is integrated for ten aromatic protons compared to seven aromatic protons in the range $\delta 5.99-7.72 \mathrm{ppm}$ for pure drug. These observations strongly suggest the formation of Schiff base product in method A. The charge transfer interaction between donor KT and acceptor TCNQ is also confirmed by observing the change in the intensities and values of chemical shifts in ${ }^{1} \mathrm{H}$ NMR spectrum of charge transfer product. It is observed that down fielding (higher shift) of most signals occurred in the spectrum of KT-TCNQ complex. The aromatic protons of KT exhibit proton signals integrating for seven protons in range $\delta 6.00-7.72 \mathrm{ppm}$ which is shifted to $\delta 6.05-7.74 \mathrm{ppm}$ integrating for eleven protons upon complexation with TCNQ. This up-field shift strongly confirms the charge transfer interaction.

\section{SEM studies}

The scanning electron microscopy is routinely used technique that reveals information about the microscopic aspects of reaction products i.e., microstructure, particle size, and the surface morphology [32]. The scanning electron micrograph of the synthesized reaction products is shown in Fig. 10. The analysis of electron micrograph of final products of reaction 

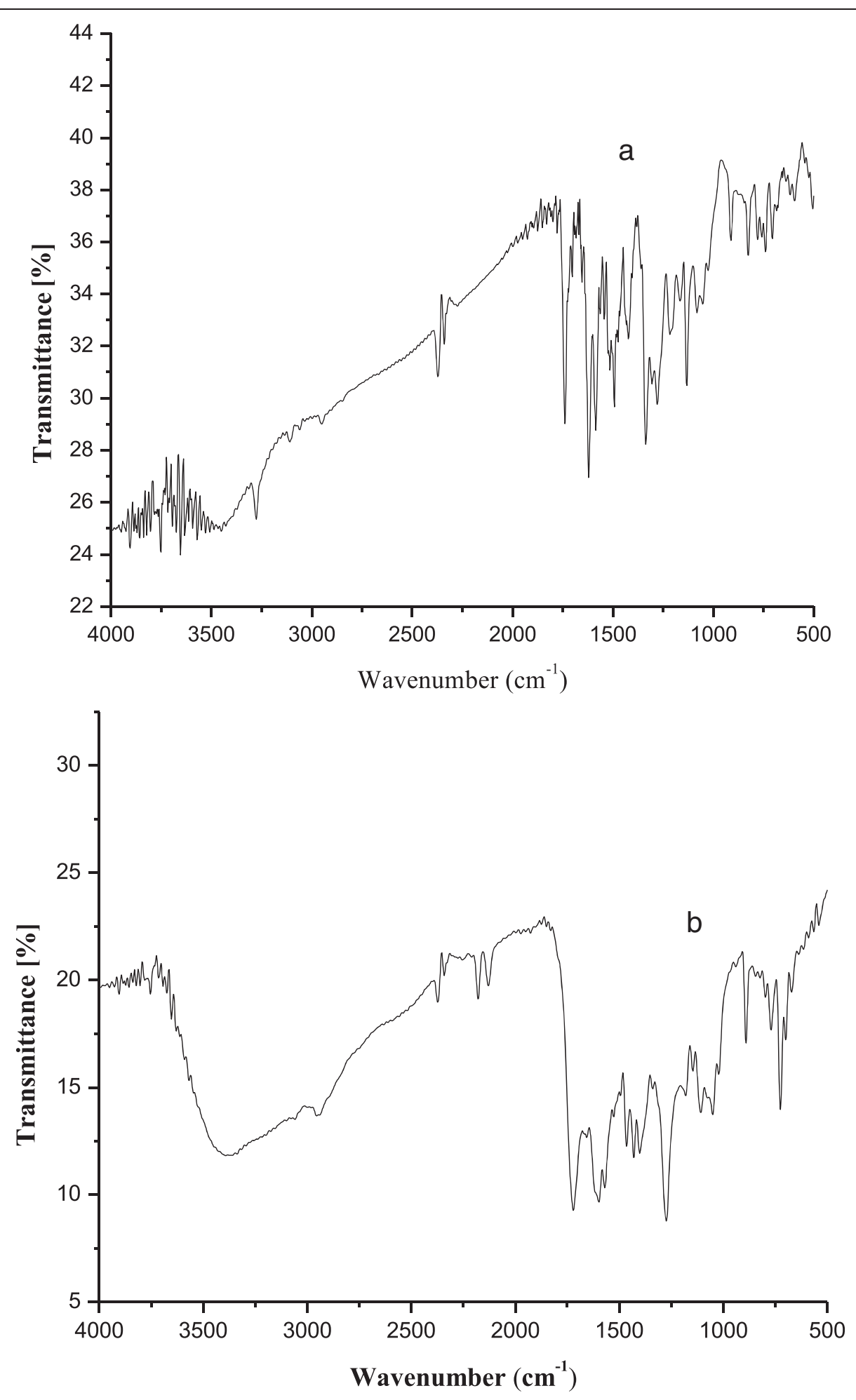

Fig. 8 Infrared spectra of a KT-DNPH and b KT-TCNQ

shows that they have particle size of $\sim 100 \mu \mathrm{m}$ and KT-DNPH displays well-defined leaf-shaped particle with the tendency to form clusters while KT-TCNQ exhibits small to large rock-shaped particles. The uniformity and similarity between the synthesized particle forms of KT reaction products indicate the presence of homogeneous distributed matrix in their morphological phases. 


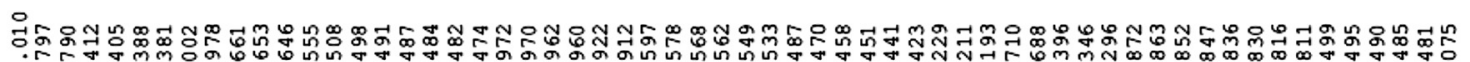

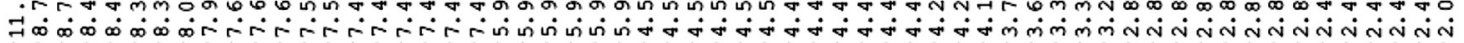

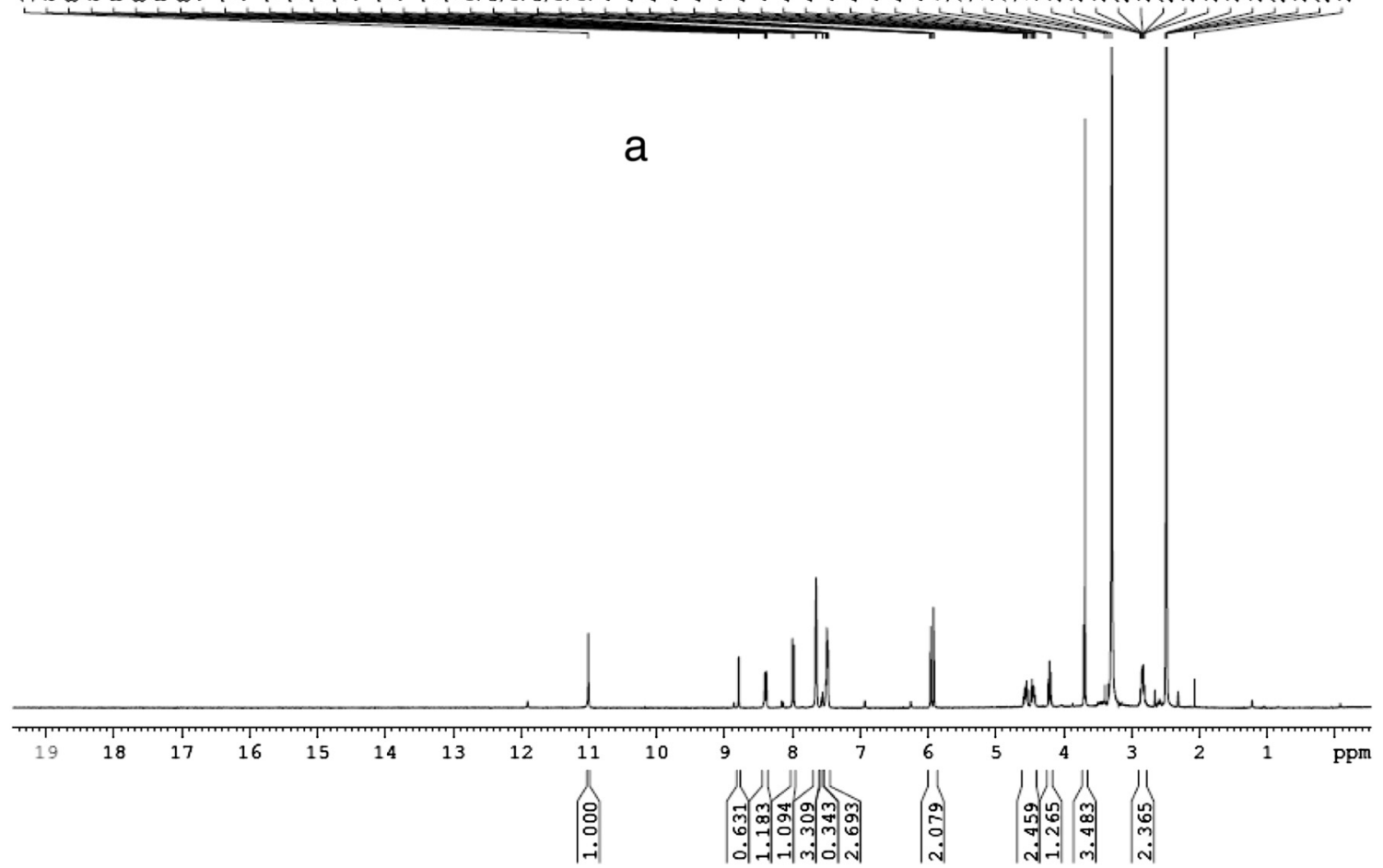

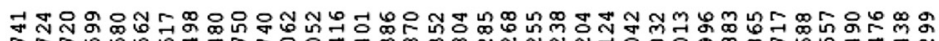

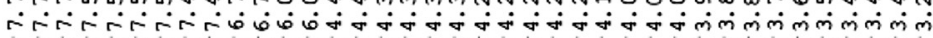

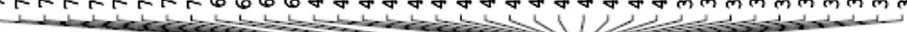

b

Auten

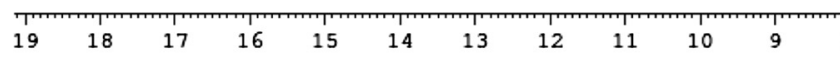

(i)

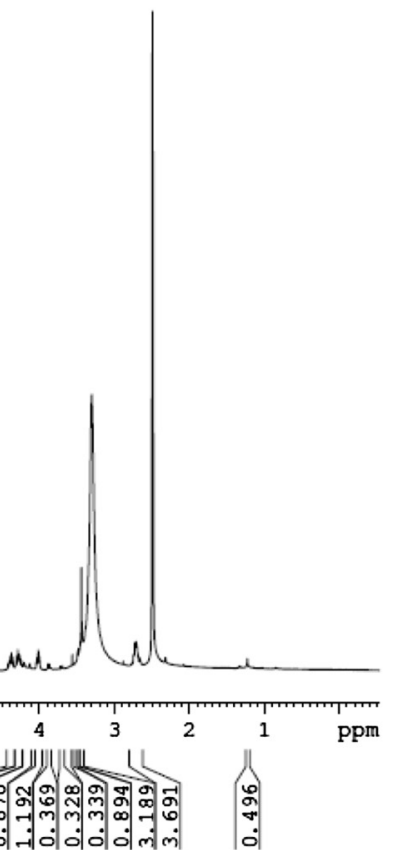

Fig. $9{ }^{1} \mathrm{H}$ NMR spectra of $\mathbf{a} \mathrm{KT}-\mathrm{DNPH}$ and $\mathbf{b} \mathrm{KT}-\mathrm{TCNQ}$ 


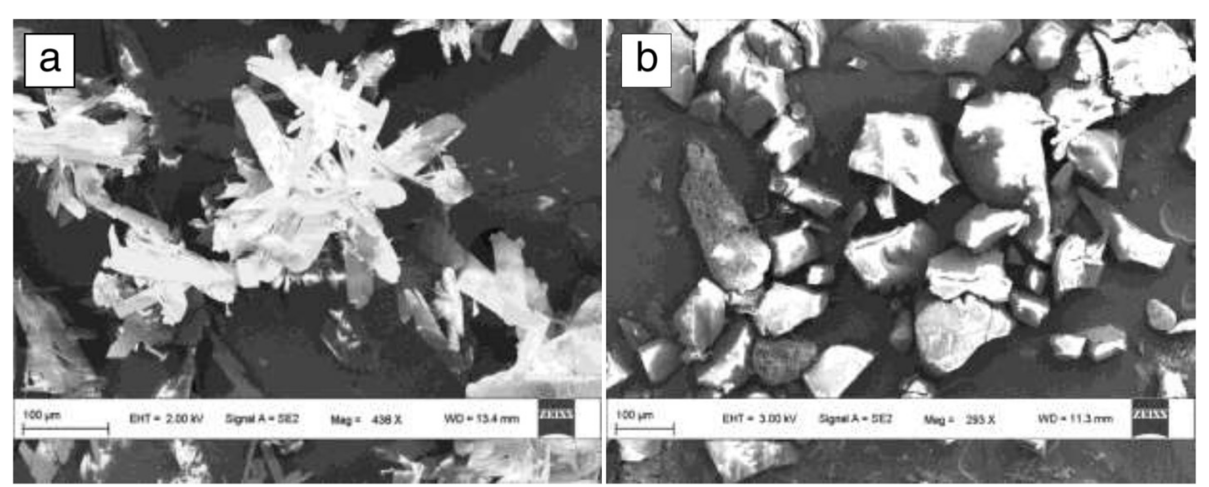

Fig. 10 SEM images of $\mathbf{a}$ KT-DNPH and $\mathbf{b}$ KT-TCNQ

\section{Conclusions}

The proposed analytical methods for the determination of $\mathrm{KT}$ in pure form and pharmaceutical formulation proved to be simple, accurate, and precise compared to the previously reported methods. The assay is rapid and requires simple sample preparation and economical since it depends on the commercially available laboratory instruments and low consumption of readily available inexpensive reagents. Furthermore, the excipients present in the formulations gave minimal interference with the proposed assay. These advantages permit the successful evaluation of these methods in pharmaceutical quality control, and so, it can be routinely applied to the pharmaceutical sample without prior treatment in the determination of KT in bulk and dosage forms. The formation of solid reaction products of KT is confirmed by FT-IR and ${ }^{1} \mathrm{H}$ NMR, and features of surface morphology are investigated by scanning electron microscopy.

\section{Competing interests}

The authors declare that they have no competing interests.

\section{Authors' contributions}

NBSI formulated, optimized, and validated the analytical methods and drafted the research findings. The contribution of carefully evaluating, critical revising, and finalization of manuscript was extended by BN. Both authors read and approved the final manuscript.

\section{Acknowledgements}

The authors gratefully acknowledge CAD Pharma Inc., Bangalore, for giving the drug sample. The authors would also like to thank the University Grants Commission for the financial assistance through BSR one time grant for the purchase of chemicals and Mangalore University for providing the required research facilities to carry out this work.

Received: 23 September 2015 Accepted: 6 November 2015 Published online: 11 November 2015

\section{References}

Abeer AH, Foziah AS, Refat MS. Spectroscopic and thermal investigations on the charge transfer interaction between risperidone as a schizophrenia drug with

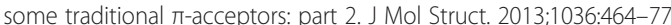

Adam AMA. Synthesis, spectroscopic, thermal and antimicrobial investigations of charge-transfer complexes formed from the drug procaine hydrochloride with quinol, picric acid and TCNQ. J Mol Struct. 2012;1030:26-39.
Adam AMA, Refat MS. Chemistry of drug interactions: characterization of chargetransfer complexes of guaifenesin with various acceptors using spectroscopic and thermal methods. Russ J Gen Chem. 2014:84:1847-56.

Arshiya F, Sayaji R, Venkateshwarlu G. Quantitative determination of drugs and pharmaceuticals using p-chloranilic acid as reagent. Int J ChemTech Res. 2012;4:79-91.

Blais $\mathrm{V}$, Zhang J, Rivest $\mathrm{S}$. In altering the release of glucocorticoids, ketorolac exacerbates the effects of systemic immune stimuli on expression of proinflammatory genes in the brain. Endocrinology. 2002;143:4820-7.

Brown CR, Moodie JE, Dickie G, Wild VM, Smith BA, Clarke PJ, et al. Analgesic efficacy and safety of single-dose oral and intramuscular ketorolac tromethamine for postoperative pain. Pharmacother. 1990;10:59S-70.

Buckley MM, Brogden RN. Ketorolac: a review of its pharmacodynamic and pharmacokinetic properties and therapeutic potentials. Drugs. 1990;39:86-109.

Dasgupta PK, Zhang G, Schulze S, Marx JN. Measurement of carbonyl compounds as the 2,4-dinitrophenylhydrazonate anion. Reaction mechanism and an automated measurement system. Anal Chem 1994;66:1965-70

Dattaray MS, Uday CN. Spectrophotometric determination of ketorolac tromethamine in its dosage forms using 3-methyl-2-benzothiazolinone hydrazone hydrochloride. Indian Drugs. 1997;34:608-9.

Dave JB, Vyas PJ, Patel CN. A validated stability-indicating high performance liquid chromatographic method for moxifloxacin hydrochloride and ketorolac tromethamine eye drops and its application in $\mathrm{pH}$ dependant degradation kinetics. Chron Young Sci. 2013:4:24-31.

DeAndrade JR, Maslanka M, Maneatis T, Bynum L, Burchmore M. The use of ketorolac in the management of postoperative pain. Orthopedics. 1994;17:157-66.

Devarajan PV, Gore SP, Chavan SV. HPTLC determination of ketorolac tromethamine. J Pharm Biomed Anal. 2000;22:679-83.

Dubey SK, Jangala H, Venkatesh CK, Saha RN, Pasha S. New chiral reverse phase HPLC method for enantioselective analysis of ketorolac using chiral AGP column. J Pharm Anal. 2012;2:462-5.

House JE. Inorganic chemistry. UK: Elsevier; 2013.

ICH Q2 (R1) (2005) Validation of analytical procedures: text and methodology. Current step 4 version parent guideline dated 27 October 1994 (complimentary guideline on methodology dated 6 November 1996 incorporated in November 2005).

Jitendra DF, Harshal PM, Rajesh YC, Vijay RP. Simultaneous spectrophotometric estimation of ofloxacin and ketorolac tromethamine in ophthalmic dosage form. Int J ChemTech Res. 2009;1:189-94.

Kamath BV, Shivram K, Shah AC. Determination of diclofenac sodium, famotidine and ketorolac tromethamine by flow injection analysis using dichloronitrophenol. J Pharm Biomed Anal. 1994;12:343-6.

Kumaraswamy G, Kumar JMR, Bhikshapathi DVRN, Venkatesh G, Spandana R. A validated RP-HPLC method for simultaneous estimation of febuxostat and ketorolac tromethamine in pharmaceutical formulations. J Drug Deliv Ther. 2012;2:173-6

Litvak KM, McEvoy GK. Ketorolac, an injectable nonnarcotic analgesic. Clin Pharm. 1990;9:921-35. 
Orlandini S, Fanali S, Furlanetto S, Marras AM, Pinzauti S. Micellar electrokinetic chromatography for the simultaneous determination of ketorolac tromethamine and its impurities. Multivariate optimization and validation. J Chromatogr A. 2004;1032:253-63.

Pratapareddy AJ, Chakravarthi IE. New spectrophotometric determination of ketorolac tromethamine in bulk and pharmaceutical dosage form. Int J Pharm Sci Res. 2012;3:4848-50.

Rajasekaran A. Spectrophotometric determination of ketorolac tromethamine in pharmaceutical dosage forms. Eastern Pharmacist. 1995;38:165-6.

Ramzia IE, Marwa AF, Fatma-Elzhraa MK, Emad MH. Derivative and derivative ratio spectrophotometric methods for the simultaneous determination of moxifloxacin hydrochloride with ketorolac tromethamine and ciprofloxacin hydrochloride with dexamethasone sodium phosphate in bulk and drop. J Chem Pharm Res. 2013;5:155-64

Razzaq SN, Ashfaq M, Khan IU, Mariam I. Stability indicating HPLC method for the simultaneous determination of ofloxacin and ketorolac tromethamine in pharmaceutical formulations. Anal Methods. 2012:4:2121-6.

Refat MS, Gobouri AA, Adam AMA, Saad HA. Novel charge-transfer complexes of 4-hexylamino-1,8-naphthalimide-labelled PAMAM dendrimer with some acceptors: a spectrophotometric study. Phys Chem Liq. 2014;52:680-96.

Refat MS, Ismail LA, Adam AMA. Shedding light on the photostability of two intermolecular charge-transfer complexes between highly fluorescent bis-1,8-naphthalimide dyes and some $\pi$-acceptors: a spectroscopic study in solution and solid states. Spectrochim Acta A. 2015;134:288-301.

Resman-Targoff BH. Ketorolac: a parenteral nonsteroidal anti-inflammatory drug. Ann Pharmacother. 1990;24:1098-104.

Sawsan AA, Maha AM, Marwa MS. Validated spectrophotometric methods for the determination of ketorolac tromethamine. Egypt J Anal Chem. 2013;22:114-29.

Sinha VR, Kumar RV, Singh G. Ketorolac tromethamine formulations: an overview. Expert Opin Drug Del. 2009;6:961-75.

Squella JA, Lemus I, Sturm JC, Nunez-Vergara L. Voltammetric behavior of ketorolac and its HPLC-EC determination in tablets. Analytical Letters. 1997;30:553-64

Stanski DR, Cherry C, Bradley R, Sarnquist FH, Yee JP. Efficacy and safety of single doses of intramuscular ketorolac tromethamine compared with meperidine for postoperative pain. Pharmacother. 1990:10:40S-4.

Tsvetkova BG, Pencheva IP, Peikov PT. HPLC determination of ketorolac tromethamine in tablet dosage forms. Der Pharmacia Sinica. 2012;3:400-3.

Vandana P, Shital P, Suwarna K, Rushikesh P, Smita V. Development and validation of HPTLC method for the simultaneous analysis of gatifloxacin and ketorolac tromethamine in eye drops. J Chem Pharm Res. 2013;5:135-41.

Yatri JB, Sandip KS, Parmeshwari JM. A validated UV spectrophotometric method for the estimation of olopatadine and ketorolac tromethamine in ophthalmic dosage form. Int J Pharm Sci Rev Res. 2013;20:118-20.

\section{Submit your manuscript to a SpringerOpen ${ }^{\circ}$ journal and benefit from:}

- Convenient online submission

- Rigorous peer review

- Immediate publication on acceptance

- Open access: articles freely available online

- High visibility within the field

- Retaining the copyright to your article

Submit your next manuscript at $>$ springeropen.com 